\title{
For a Holistic and Systemic Approach to IP Law
}

\author{
Gustavo Ghidini
}

(C) Max Planck Institute for Innovation and Competition, Munich 2014

It is almost superfluous to point out how complicated the overall IP regulatory framework has become compared to the classic representation thereof set out in the great Paris and Berne Conventions, and related national legislations at the end of the 19th century - a situation that has intensified especially in the past 50 years with the unrelenting emergence of new technologies and forms of communication.

In short, the intrinsic diversity of the subject matter, function and key features of the single fundamental paradigms (patents, trademarks and copyright) has been more and more "aggrieved" by: (a) the internal diversification of the paradigms themselves (just think of the variety of models for protecting technological innovation or the array of neighbouring rights regimes within copyright law); (b) the increasing reciprocal "hybridisation" and overlapping of the paradigms in question (just think of the multiform protection for industrial designs); and (c) the acknowledgement of the necessary "interference" of competition law (unfair competition and antitrust) with IP law. All this, moreover, being the target of an ever-growing regulatory deluge, both domestic and international, in particular at the EU level.

Now, such ongoing fragmentation of the IP regulatory framework has fostered the rise of a line of thought (and teaching) that seeks to construe the single IP paradigms in isolation: not just one from the other but also from the overall regulatory framework concerning the activities and interests involved in the exercise of intellectual property rights - a framework that obviously includes, at its apex, constitutional principles.

That "separatist" trend (which can realistically be associated with a method of rulemaking increasingly inspired by sectorial interests and thus ever more

G. Ghidini ( $₫)$

Professor of IP and Competition Law (University of Milan and Luiss University in Rome)

Milan, Italy

e-mail: ghidini@ghidini-associati.it 
insensitive to systemic consistency), has often undoubtedly contributed to producing in-depth analytical results. But if taken to an extreme, it exposes the interpreter to the risk of sacrificing two paramount methodical guidelines that can be labelled as consistency and coherence respectively. ${ }^{1}$

Consistency and coherence, on the one hand, mean interpreting the rules on a specific paradigm in a manner that does not contradict the rules on the same subject matter that another paradigm expresses in relation to a distinct protective function (and as such intrinsically "non-conflicting"). In other words, the need for the right hand to know what the left hand is doing, avoiding otherwise open contradictions within IP law.

The other need that a reconstruction of IP law based on separate compartments risks sacrificing is that of interpreting IP law consistent with the constitutional principles referable to the activities involved, and the claims advanced, within the context of conflicts of interest between various IPR holders and between IPR holders and third parties, arising out of the exercise of intellectual property rights. A bundle of principles, that in essence can be traced back to the two fundamental liberties of freedom of enterprise (and hence competition) and freedom of expression (active and passive: the production and spreading of culture and enjoyment of access thereto).

Now, such principles should play a primary, if not indeed overarching role in interpreting those paradigms under a systemic approach. But such approach would easily "lose the name of action" in a context that construes the various paradigms separately.

There is more. Those constitutional principles express the ethical-political canons of the organized community: canons historically formulated and established through often heated debates, and more, among various social stakeholders. Neglecting those principles or not effectively valuing them as the key to construing the rules leads to the further and even more serious risk of not understanding where a certain line of interpretation leads, and why, or put another way, "who gains, who loses" following the adoption of one line of interpretation rather than another.

The risk, finally, is that jurists will be reduced to "techies": brilliant and up-todate specialists well able to count the trees but not see the forest, nor sense the wind that blows through it. Or worse still, jurists very adept in using exegetics and specialist knowledge to technically mask solutions serving undisclosed policy objectives - if not particular interests.

\section{Reference}

MacCormick N (1984) Coherence in legal justification. In: Peczenik A, Lindhal L, van Roermund B (eds) Theory of legal science: Proceedings of the Conference on Legal Theory and Philosophy of Science, Lund, Sweden, December 11-14. D. Reidel, Dordrecht/Boston/Lancaster, pp 235-251

\footnotetext{
${ }^{1}$ MacCormick (1984).
} 